\title{
Reduction Corporoplasty
}

\author{
Tariq S. Hakky ${ }^{1}$, Daniel Martinez ${ }^{1}$, Christopher Yang ${ }^{1}$, Rafael E. Carrion ${ }^{1}$ \\ ${ }^{1}$ Department of Urology and Division of Andrology, University of South Florida, FL, USA
}

\section{ABSTRACT}

Objective: Here we present the first video demonstration of reduction corporoplasty in the management of phallic disfigurement in a 17 year old man with a history sickle cell disease and priapism.

Introduction: Surgical management of aneurysmal dilation of the corpora has yet to be defined in the literature.

Materials and Methods: We preformed bilateral elliptical incisions over the lateral corpora as management of aneurysmal dilation of the corpora to correct phallic disfigurement.

Results: The patient tolerated the procedure well and has resolution of his corporal disfigurement.

Conclusions: Reduction corporoplasty using bilateral lateral elliptical incisions in the management of aneurysmal dilation of the corpora is a safe an feasible operation in the management of phallic disfigurement.

\section{ARTICLE INFO}

ARTICLE INFO Available at: www.brazjurol.com.br/videos/march_april_2015/Hakky_397_398video.htm

Int Braz J Urol. 2015; 41 (Video \#3): 397-8

Submitted for publication:

November 01, 2014

Accepted after revision:

December 09, 2014
Correspondence address:
Rafael E. Carrion, MD
2 Tampa General Circle
Tampa, FL 33602, USA
E-mail: rcarrion@health.usf.edu




\section{EDITORIAL COMIMENT}

In this video by Hakky et al., the authors nicely depict a surgical technique of reduction corporoplasty using bilateral lateral elliptical incisions in the management of aneurysmal dilation of the corpora cavernosa. This surgical approach is both novel and nicely depicted by the authors. In the continual goal of penile reconstructive surgery to preserve/optimize penile length and functionality, the present surgical approach adds to our present surgical. The merits of this versus other techniques are ultimately at the discretion of the surgeon appreciating his personal surgical outcomes with a given technique weighed along with the expectations and treatment goals of the individual patient.

Philippe E. Spiess, MD Video Section Editor, International Brazilian Journal of Urology E-mail: Philippe.Spiess@moffitt.org 